\title{
LA SEGUNDA REVALORIZACIÓN DEL CAMPESINADO EN MÉXICO: DE “POBRES” Y “POBLACIÓN REDUNDANTE” A SUJETOS PRODUCTIVOS Y DE DERECHOS
}

\section{The Second Revaluation of Pesantry in México: From “Poor” and “Redundante Population" to Productive Subjects and Subjects of Rights}

\author{
Víctor Suárez Carrera \\ La civilización mesoamericana es una civilización negada, \\ cuya presencia es imprescindible reconocer. \\ México Profundo, Guillermo Bonfil Batalla
}

Podemos concluir que la promoción de la agricultura campesina, lejos de ser un sueño romántico o un regreso al pasado, es una solución de futuro. La agricultura campesina: ilusión o desafío, François Houtart

Estamos ante una disyuntiva epocal que nadie puede soslayar. El orden clasista, colonial y patriarcal que además de destruir la naturaleza explota a los trabajadores, somete a los colonizados, oprime a las mujeres y excluye a los jóvenes robándoles el futuro, debe ser dejado atrás. Y la vía más promisoria es la que señalan los indígenas y campesinos.

Escuchemos sus voces. ¿Quién podrá salvarnos?, Armando Barta

\footnotetext{
${ }^{1}$ Director Ejecutivo de la Asociación Nacional de Empresas Comercializadoras de productores del Campo, ANEC, A.C.

Correo electrónico: victor.suarez@anec.org.mx

Fecha de recepción: 2405 16; Fecha de aceptación: 021216.
}

(cc) BY-NC-ND Páginas 14-45. 
Resumen: A lo largo de la historia de México los pueblos indígenas y los campesinos han sido sometidos, despojados, explotados, negados y desvalorizados con la excepción de un breve periodo: la primavera campesindia, primera revalorización del campesinado en México.

Gracias a la revolución social de 1910 y posteriores luchas, los campesinos y pueblos indígenas conquistaron el derecho a la tierra, a tener una vida mejor y a ser considerados como parte del proyecto nacional.

Con la instauración del neoliberalismo en 1982, se abre un nuevo ciclo de exclusión y desvalorización, mismo que pone fin al pacto Estado-campesinos establecido en la Constitución de 1917.

La primera primavera campesindia y las resistencias y alternativas de las últimas décadas constituyen un activo fundamental en la lucha por la segunda revalorización campesina. Ésta representa no solamente una reivindicación histórica para una clase-sujeto específica, sino también una opción de futuro para nuestro país.

Palabras clave: sujeto social, pequeño productor, campesinos, pueblos indígenas, potencial productivo, cambio social.

Abstract: Throughout the history of Mexico indigenous peoples and peasants have been dominated, dispossessed, exploited, denied and devaluated, with the exception of a brief period of time: the campesindia —indigenous peasantry — spring. This period represented the first revaluation of the peasantry in Mexico. Peasants and indigenous peoples conquered the right to the land, to have a better life and to be considered as part of the national project, thanks to the social revolution of 1910 and later struggles.

In 1982, the introduction of neoliberalism started a new cycle of exclusion and devaluation, which puts an end to the State-peasants Covenant established in the Constitution of 1917.

The first campesindia (indigenous peasantry) spring and resistances and alternatives in recent decades, constitute a fundamental asset in 
the fight for the second peasant revaluation. It is not only a historical claim to a specific class-subject, but also an option for the future for our country.

Keywords: social subject, small producer, peasants, indigenous peoples, productive potential, social change.

\section{Introducción}

Este artículo pretende fundamentar la necesidad y viabilidad de la segunda revalorización campesindia ${ }^{2}$ en la historia de México: la primavera campesindia del siglo XXI. Representa no solamente la reivindicación histórica para una clase-sujeto específica, sino también una opción de futuro con la que construir con toda la sociedad una salida democrática, nacionalista, incluyente, social y sustentable a la gran crisis del sistema económico y político oligárquico, neoliberal y neocolonial en nuestro país.

En la primera parte, llamada "La primera revalorización campesindia en México", se revisa el proceso histórico de despojo, desvalorización, negación y exclusión de los pueblos indígenas y del campesinado a lo largo de la Colonia, la Independencia, la Reforma y el Porfiriato. Se muestra como aun en los proyectos nacionales emancipadores como el de la Independencia y la Reforma, la condición de desvalorización de los campesindios persistió e, incluso, se agravó. Después de cuatro siglos y una revolución social — la Revolución de 1910—,

\footnotetext{
${ }^{2}$ Campesindios: neologismo acuñado por Armando Bartra que expresa la existencia de un nuevo sujeto-clase en construcción desde las orillas del capitalismo global en su fase neoliberal y de la gran crisis. "Así campesinos y etnias colonizadas son conjuntos que se intersectan extensamente — conformando lo que bien podríamos llamar campesindios — y también las dos caras de un cuerpo social complejo que, siendo contemporáneo como el que más, se inserta en el orden imperantes en el modo de la exteriorización tanto socioeconómica como identitaria ... La superación de estas falsa antinomia no será posible sin poner al día el viejo concepto de clase por también los conceptos emergentes de identidad y localidad”, en Armando Bartra, 2014, El hombre de hierro, límites sociales y naturales del capital en la perspectiva de la gran crisis, Ítaca, México; Para profundizar en el concepto, ver también Tiempos de mitos y carnaval, indios, campesinos, revoluciones, 2011, Ítaca/UAM, 2011; y Campesindios. Aproximaciones a los campesinos de un continente colonizado, 2010, CIDES/Universidad Mayor de San Andrés, Bolivia.
} 
los campesindios conquistaron por primera vez en la historia de México su condición de sujetos de derechos colectivos e individuales y su derecho a ser parte de la nación, de un nuevo proyecto nacional, del México postrevolucionario. Se trató de una verdadera etapa de derechos conquistados a través de una revolución social y de luchas agrarias ininterrumpidas a lo largo de poco más de dos generaciones.

También pondera la enorme hazaña histórica del campesinado mexicano que significó la restitución de las tierras comunales de los pueblos indígenas, el reparto y fin del latifundismo, la creación del ejido y el impulso productivo de la nueva agricultura mexicana. Este hecho, a juicio del autor, no debe olvidarse ni menospreciarse ya que constituye uno de los pilares centrales para la conquista de la segunda revalorización campesina en México.

En la segunda parte, se reseña cómo la ofensiva del capital global en su fase neoliberal pone fin a la primera revalorización campesina en México y vuelve a excluir a los campesinos del proyecto nacional, recategorizándolos y reduciéndolos a una nueva condición: la de "pobres" y "población redundante".

Se muestra, asimismo, cómo el Estado mexicano ha emprendido una estrategia transexenal contra los campesindios a través de las llamadas reformas estructurales de primera, segunda y tercera generación llevadas a cabo entre 1982 y 2016.

Se enfatiza de igual manera la importancia de entender y visibilizar el proceso ideológico mediante el cual las políticas neoliberales han pretendido negar a los campesindios su carácter de sujetos de derechos, sujetos productivos y su enorme potencial productivo-social-culturalecológico para contribuir a la resolución de los grandes problemas nacionales. Entender esto, desde el punto de vista del autor, es crucial para la autooganización de los campesinidios y su construcción en clase como precondición para la conquista de la segunda revalorización del campesinado de México.

En la tercera parte, se expone cómo las múltiples, diversas y persistentes resistencias y alternativas campesindias que han desplegado a lo largo y ancho del país en las últimas tres décadas, constituyen un activo fundamental y una condición de viabilidad para poner fin a la 
ofensiva neoliberal y conquistar una segunda revalorización campesina en el marco de un nuevo proyecto de nación.

\section{La primera revalorización del campesinado en México: la primavera campesindia}

A lo largo de la historia de México — desde la Colonia hasta nuestros días - los pueblos indígenas y los campesinos han sido sometidos, despojados, explotados, negados y desvalorizados, con la excepción de un breve periodo: la primavera campesindia.

Con la Independencia de México, los pueblos indígenas lograron la reducción de las alcabalas y la abolición formal de los tributos (LeónPortilla, 2011). En materia agraria, Morelos estableció en su "Plan del gobierno americano", con fecha 16 de noviembre de 1810 , que "se les entregarán sus tierras a los pueblos en restitución de las que hayan usurpado los europeos" (León-Portilla, ídem: 43). Más allá de las declaraciones y aspiraciones emancipadoras de los dirigentes independentistas, en los hechos,

a partir de la Constitución de Cádiz (1812), y luego en las de Apatzingán (1814) y en la que se expidió en 1824 consumada la Independencia y establecida la República, los indígenas fueron perdiendo los derechos en que se fundaba su personalidad jurídica. Al hacerse a un lado las distinciones étnicas, poco a poco fueron desapareciendo las antiguas repúblicas de indios. La imposibilidad de esgrimir derechos que les reconocían las Leyes de Indias trajo consigo nuevas formas de marginación. La propiedad comunal de las tierras, las formas de gobierno indígena, la salvaguarda de sus lenguas y de sus usos y costumbres quedaron en grave peligro de desaparecer... Los indios, tanto en el contexto novohispano como entre los mismos insurgentes, vieron disminuidos sus derechos tradicionales basados en su carácter de comunidades o república de indios. Por el contrario, en varios casos, las pérdidas de sus tierras fueron en aumento. $\mathrm{Y}$ a pesar de que jurídicamente, la condición de indio perdió sus significado, el desdén y desprecio respecto de ellos prevalecía y aun se incrementaba entre gran parte de la población... Los pueblos indígenas, cuya existencia se vio 
perturbada con las disposiciones igualitarias, pudieron percatarse de que la obtención de la Independencia lejos de mejorar sus condiciones de vida, había dado entrada a mayores problemas (León-Portilla, ídem: 68-69).

En este mismo sentido, Guillermo Bonfil afirma categórico que:

El surgimiento y la consolidación de México como un Estado independiente en el transcurso turbulento del siglo XIX no produjo ningún proyecto diferente, nada que se aparte de su intención última de llevar al país por los senderos de occidente. Las luchas entre conservadores y liberales sólo expresan concepciones distintas de cómo alcanzar esa meta, pero en ningún momento la cuestionan. Al definir la nueva nación mexicana se le concibe culturalmente homogénea, porque en el espíritu (europeo) de la época domina la convicción de que un Estado es la expresión de un pueblo que tiene la misma cultura y la misma lengua, como producto de una historia común (Bonfil, 1989: 103-104).

La Reforma liberal si bien permitió afirmar la independencia nacional, repeler las invasiones extranjeras, defender la República y establecer el Estado laico, entre otros grandes logros históricos, al mismo tiempo sentó las bases para la exclusión y el despojo masivo de las tierras de los pueblos indígenas, mismos que se materializaron durante el Porfiriato.

En efecto, el discurso liberal de los reformistas —igualdad entre los ciudadanos, propiedad privada como base de la ciudadanía y el progreso- sirvió de argumento "científico" para negar la existencia de una nación multicultural y, con ello, los derechos de los pueblos indígenas. Así, en el marco de la lucha político-militar contra los conservadores, los reformistas expidieron en junio de 1856 la llamada Ley Lerdo de desamortización de bienes en manos de corporaciones eclesiásticas y civiles.

La Ley Lerdo no solamente permitió la nacionalización y privatización de las tierras en manos de la Iglesia - principal terrateniente de la época- suprimiendo de esta manera la base material del poderío 
de los conservadores, sino que también afectó a la existencia de las corporaciones civiles, es decir, a los pueblos indígenas y su régimen de propiedad comunal de las tierras.

La Constitución liberal de 1857 fue aún más lejos. De acuerdo con Miguel León-Portilla, se suprimió por completo la figura de la propiedad comunal de la tierra: "Ninguna corporación civil o eclesiástica, cualquiera que sea su carácter, denominación u objeto, tendrá capacidad legal para adquirir en propiedad o administrar por sí bienes raíces, con la única excepción de los edificios destinados inmediata y directamente al servicio u objeto de la institución”. De acuerdo con el pensamiento de los constituyentes liberales,

la supresión de la propiedad comunal debía resultar en beneficio de los pueblos indígenas ... Si ya antes los pueblos indígenas se habían esfumado como tales, en aras de una pretendida homologación jurídica, es decir, de la igualdad, con la Constitución de 1857 se dio otro paso para hacerlos desaparecer en la realidad misma, social y territorial. Se pensó que suprimiendo la propiedad comunal, considerada como una de las causas del atraso de los indios, se lograría su participación plena en el contexto del proyecto nacional concebido para México, como país de cultura europea en el que las antiguas etnias debían ser asimiladas (León-Portilla, ídem: 74-75).

Durante el Porfiriato, la exclusión, el despojo y el sometimiento de la población indígena llegó a los extremos del genocidio, la aniquilación de la propiedad comunal y el restablecimiento de la esclavitud campesindia. La Ley de colonización y compañías deslindadoras de 1883 fue uno de los instrumentos legales para tales efectos.

De esta manera, la Independencia, la Reforma y el Porfiriato, representaron un siglo más de desvalorización, despojo y exclusión de los pueblos indígenas y de los campesinos. Tuvo que llegar la Revolución de 1910 para conquistar la primera revalorización campesina en la historia de México, etapa que el autor denomina "la primavera campesindia”. 
La primavera campesindia duró "muy poco": de 1915 a 1982. ${ }^{3} \mathrm{El}$ derecho a ser considerados parte del proyecto nacional, tener derechos propiamente dichos, y a acceder a la restitución de las tierras comunales y al reparto agrario para constituir el ejido duró únicamente dos generaciones y un poco más.

Salir de la exclusión, el despojo, la esclavitud, la servidumbre, la invisibilidad y la negación de todo derecho no fue fácil: fue necesaria una revolución social y décadas de luchas ininterrumpidas para lograr el desmantelamiento del latifundio y el reparto agrario. De esta manera, entre 1918 y 1988, 106 millones de hectáreas, 53\% del territorio nacional, pasaron a manos campesindias por medio de 31 mil 500 ejidos y comunidades y el otorgamiento de derechos agrarios para 5.6 millones de hombres y mujeres del medio rural. Si a estas cifras agregamos la existencia de 1.6 millones de pequeños propietarios, la mayoría de los cuales tiene cinco hectáreas o menos, con 35.7\% de la superficie nacional, resulta que casi $90 \%$ del territorio nacional está en manos campesindias (Robles, 2012: 311).

Toda una hazaña histórica si consideramos que durante la reforma liberal —-Ley Lerdo de 1856 - y, sobre todo, en la dictadura porfirista -Ley de Colonización y Compañías Deslindadoras de 1883- se despojó a las comunidades indígenas de casi 50 millones de hectáreas; teniendo en cuenta que para 1910 el país tenía la siguiente estructura agraria: cinco mil 932 haciendas poseían 94\% de la tierra; 32 mil 557 rancheros eran propietarios de cinco por ciento, y el uno por ciento restante correspondía a comunidades y pueblos. Del área total del México, tres y medio millones de campesindios subsistían como peones acasillados y aparceros, y 40\% estaba en manos de media docena de latifundios (Córdova, 1973: 42-43).

A pesar de la derrota estratégica de las fuerzas campesinas y de su proyecto histórico — el Plan de Ayala y el Pacto de Xochimilco-, el impulso de la revolución campesindia fue capaz de obligar a las fuerzas constitucionalistas-carrancistas a establecer un nuevo Pacto Social entre el nuevo Estado revolucionario y los campesinos, mismo que se

\footnotetext{
${ }^{3}$ A partir de la ley agraria de 1915 hasta 1982, año en que formalmente nuestro país adopta la política macroeconómica neoliberal.
} 
materializó en el artículo 27 de la Constitución de 1917 y en una política de Estado de inclusión social y de inversión productiva para el desarrollo del nuevo agrocampesino.

Gracias a este Pacto Social, los campesindios fueron valorizados por primera vez en la historia de México como sujetos de derechos - derecho a la tierra, derecho al agua, derecho al territorio, derecho a la educación-, como sujetos productivos — productores de alimentos y fibras para el crecimiento urbano y la industrialización- y como sujetos portadores de la identidad y valores nacionales. Lo anterior no sólo fue producto de la revolución campesina de 1910 a 1923, sino de los recurrentes alzamientos campesinos e indígenas por todo el territorio nacional que obligaron al cumplimiento y a la profundización del compromiso del Estado con los campesinos durante el Cardenismo (1934-1940).

Si bien el reparto agrario — ver cuadro final de Reparto Agrario 19101992 - no cesó en la etapa postcardenista y preneoliberal, de 1940 a 1980, la primavera campesindia tendió a debilitarse por la creciente pérdida de la autonomía de las organizaciones y movimientos agrarios y su creciente corporativización como brazo campesino del partido en el poder ${ }^{4}$ a través de la Confederación Nacional Campesina (CNC). Otro factor fue la llegada al poder de Manuel Ávila Camacho - 19401946 - y de Miguel Alemán -1946-1952 - como representantes de las fuerzas neolatifundistas y anticampesinas. En este periodo se intentó frenar y revertir el reparto agrario con la expedición de los certificados de inafectabilidad agrícola y ganadera al mismo tiempo que se estableció una política de fomento productivo que privilegió al sector de grandes agricultores del norte-noroeste en detrimento del sector campesino.

Durante la primavera campesindia, gracias a la reforma agraria, a las políticas de fomento productivo y a una política de precios agrícolas favorable, los campesinos de México — los pequeños y medianos productores del país - fueron capaces de producir y abastecer los alimentos y

\footnotetext{
${ }^{4}$ Partido Nacional Revolucionario, PNR (1929-1938), cambiando de nombre en 1938 a Partido de la Revolución Mexicana, PRM (1938-1946), y en 1946 a Partido Revolucionario Institucional, PRI (1946 a la fecha).
} 
fibras que requirió el crecimiento industrial y la acelerada urbanización de 1940 a 1980. Este hecho prueba por sí solo la capacidad productiva del pequeño productor y también la rápida capacidad de respuesta cuando se reconocen sus derechos y se establecen políticas agrícolas y comerciales favorables a la producción campesina. Durante esta etapa se dio un acelerado crecimiento del producto interno bruto (PIB) del sector agropecuario y forestal, con tasas del 4 al $6 \%$ promedio anual, lo cual es representativo si lo comparamos con épocas más recientes donde las tasas de crecimiento promedio anual del PIB agropecuario (1982-2015) han oscilado entre 1.5 y $2 \%$.

La primavera campesindia también involucró un movimiento cultural de reivindicación de las raíces y valores de lo indígena, de lo campesino. La identidad y orgullo del México postrevolucionario se alimentó de la exaltación del legado ancestral de México. En el campo de la plástica destacan pintores como Diego Rivera, José Clemente Orozco, David Alfaro Siqueiros y Frida Kahlo. En el de la música Carlos Chávez, José Pablo Moncayo y Silvestre Revueltas. En literatura sobresalen Mariano Azuela, José Vasconcelos, Martín Luis Guzmán, José Rubén Romero, Francisco L. Urquiza, Gregorio López y Carlos Fuentes, Rafael F. Muñoz, José Mancisidor, Nellie Campobello, Francisco Rojas González, Mauricio Magdaleno, José Revueltas, Agustín Yáñez y Juan Rulfo, entre otros (León-Portilla, ídem: 97).

Los campesinos y los pueblos indígenas, con la tierra en sus manos y una política de Estado a su favor, recobraron y les fue reconocido su papel de protagonistas en la historia nacional. De esta forma, los campesinos de México fueron capaces de conquistar la primera revalorización campesina desde la Conquista, si bien insuficiente y en condición de clase subalterna y explotada por la lógica del capital.

Sin embargo, la primavera campesindia fue debilitándose hacia la década de los setenta y, finalmente, el Pacto Social post-revolucionario Estado-campesinos fue roto con el establecimiento del neoliberalismo en México a partir de 1982. Los campesinos y los pueblos indígenas volvieron a ser excluidos del proyecto nacional y a ser considerados como "población redundante", iniciando un nuevo ciclo de desvalorización del campesinado mexicano que se prolonga hasta nuestros días. 
Esta gran hazaña campesindia representa un activo valioso para la resistencia actual frente a la ofensiva neoliberal y de igual manera para la conquista de la segunda revalorización campesina en México.

Diversos autores 5 enfatizan en los límites emancipadores de la revolución mexicana - "no emancipó ni mejoró las condiciones de vida de los campesinos e indios", "la revolución campesina imposible", "fue subordinada a la hegemonía de la burguesía antiporfirista", "no fue anticapitalista" - y minimizan las repercusiones de la primavera campesindia mexicana: "los campesinos fueron corporativizados por el poder". Sin embargo, no debe olvidarse que uno de sus grandes logros —el fin del latifundismo, la restitución de las tierras comunales, el reparto agrario y la inclusión campesindia en un proyecto nacional- es aún tarea pendiente y una aspiración profunda del campesinado y de los pueblos indígenas de la mayoría de los países de África y Asia, y de toda América Latina con excepción de Cuba, Bolivia y Venezuela.

\section{Ofensiva neoliberal contra el campesinado en México}

Con el establecimiento del neoliberalismo en 1982 concluyó definitivamente la primavera campesindia y se estableció una nueva ofensiva contra el campesinado: la ofensiva neoliberal impulsada por el capital transnacional y los intereses hegemónicos de Estados Unidos en la era del capitalismo global.

A lo largo de más 30 años se ha construido deliberadamente una falsa imagen del campesinado mexicano clasificándolo como "pobre", "improductivo", "atrasado" y "premoderno", y ha sido despojado de su condición intrínseca como sujeto productivo y de su papel histórico en la construcción del México contemporáneo.

\footnotetext{
${ }^{5}$ León-Portilla, Miguel, 2011, "Críticas aparte, una realidad es innegable: los repartos y restituciones en el caso de las comunidades indígenas no trajeron consigo el mejoramiento sustancial de sus condiciones de vida", p. 96; Córdova, Arnaldo, 1973, "La revolución campesina: un imposible", p. 144; Bonfil Batalla, Guillermo, 1989, "Sin restar importancia a los contenidos agraristas de la Constitución de 1917 y sin negar los méritos de los mejores momentos de la Revolución hecha gobierno, como el periodo cardenista, es necesario reconocer que la esencia misma del proyecto zapatista fue eliminada y que sólo se incorporaron en el programa triunfante de la Revolución aquellas demandas que parecían ser compatibles con las metas que finalmente definieron el carácter de la Revolución vencedora”, p. 105.
} 
Esta deformación ideológica e histórica ha sido parte medular de la estrategia para imponer el neoliberalismo en el sector agroalimentario; ha contado con la fundamentación "científico-técnica" y la promoción activa de los organismos multilaterales - Fondo Monetario Internacional, FMI; Banco Mundial, BM; Organización para la Cooperación y el Desarrollo, OCDE- y la ejecución de los gobiernos federales en turno.

El gobierno mexicano y sus ideólogos "modernizadores del campo", entre los que destacaron Santiago Levy y Luis Téllez, fueron aún más lejos: decretaron la "no existencia" y la condición de "población redundante” y, por tanto, desechables, del campesinado mexicano.

En palabras de Boaventura de Sousa Santos, de acuerdo con una de sus cinco lógicas de producción de no existencia, "[ésta] es producida bajo la forma de una inferioridad insuperable, en tanto que natural. Quien es inferior lo es porque es insuperablemente inferior, y por consiguiente, no puede constituir una alternativa creíble frente a quien es superior" (De Souza, 2009: 111).

Años antes, y en el mismo sentido, Guillermo Bonfil Batalla afirmaba que:

Una característica sustantiva de toda sociedad colonial es que el grupo invasor, que pertenece a una cultura distinta de la de los pueblos sobre los que ejerce su dominio, afirma ideológicamente su superioridad inmanente en todos los órdenes de la vida y, en consecuencia, niega y excluye la cultura del colonizado ... Así, los diversos proyectos nacionales conforme a los cuales se ha pretendido organizar a la sociedad mexicana en los distintos periodos de su historia independiente, han sido en todos los casos proyectos encuadrados exclusivamente en el marco de la civilización occidental, en los que la realidad del México profundo no tiene cabida y es contemplada únicamente como símbolo del atraso y obstáculo a vencer (Bonfil, ídem: 11).

Con la producción de la no existencia del campesinado y la negación del México profundo, los gobiernos neoliberales decretaron la inviabilidad de la agricultura campesina en el marco de la modernidad neoliberal y transmutaron a los campesinos e indígenas a la condición de 
pobres, elevando a política de Estado su exclusión y su "inevitable" descampesinización y migración a los sectores "dinámicos” de la economía de la nueva tierra prometida: la "América del Norte" del TLCAN.

Sin ninguna evidencia histórica ni demostración empírica alguna, y sólo con el argumento de que "a mayor escala en las unidades de producción rural (UPR), mejor asignación de los recursos y mayor productividad y competitividad", la política del Estado neoliberal (1982-2016) consistió en la canalización de apoyos productivos en forma exclusiva para los grandes agricultores que se convirtieron en los principales beneficiarios del régimen, quedando excluidas $90 \%$ de las pequeñas y medianas UPR. Estas últimas, ya despojadas ideológicamente de su condición de sujetos productivos y clasificadas como "pobres", han sido objeto exclusivamente de ayuda para pobres, es decir, asistencialismo público y filantropía privada.

Destacan entre los programas asistencialistas llevados a cabo desde Salinas hasta el sexenio de Enrique Peña Nieto los siguientes: Solidaridad, Oportunidades, Progresa, Prospera y Procampo-Proagro. Los programas de fomento productivo que han sido canalizados mayoritariamente a las grandes UPR son, entre otros, el crédito canalizado por la banca de desarrollo y los programas de apoyos a la comercialización, de infraestructura, de activos productivos, de maquinaria agrícola, de capitalización, de agricultura protegida y de clusters, de la Sagarpa. ${ }^{6}$

De esta forma, durante más de tres décadas se ha concentrado la inversión productiva en un sector minoritario de UPR, por lo que el campo y la nación han inhibido y desperdiciado la energía y el potencial productivo de alrededor de cinco millones de unidades de producción familiar, provocando un sinfín de resultados adversos, entre los cuales sobresalen: el acelerado incremento de la desigualdad y la pobreza en el campo, el estancamiento económico sectorial, la dependencia alimentaria y la malnutrición, el desempleo y migración crecientes, así como un grave deterioro de la cohesión social, de los recursos naturales y del medio ambiente.

Por último, la trasmutación neoliberal del campesinado de sujeto productivo a pobre ha operado como una profecía autocumplida,

${ }^{6}$ Para mayor abundamiento consultar: www.subdisiosalcampo.org y www.valoralcampesino.org 
empobreciéndolo en forma creciente y transformándolo como votante cautivo a través de los múltiples y crecientes programas individualizados e individualizantes para el combate a la pobreza.

El proceso de desvalorización neoliberal del campesinado no ha sido solamente resultado de un prejuicio ideológico neocolonial y neoliberal de la clase en el poder y de los grupos gobernantes en turno. En realidad, ha respondido a lógicas precisas de acumulación orientadas a tres objetivos centrales: i) la privatización del sistema alimentario y nutricional mexicano y su control por las corporaciones globales; ii) la reasignación masiva de la mano de obra depauperada del campo para el sector dinámico de la agricultura - incluyendo el subsector de estupefacientes_- para el sector maquilador y para la desfalleciente economía estadounidense, y iii) el despojo y depredación de los territorios campesindios y recursos naturales.

Se trata de una agenda de reestructuración profunda del capitalismo global con la complicidad de las élites económicas y políticas locales para convertir a nuestro país en un Estado neocolonial y tributario (Montoya et alli, 2015: 21-37).

El nuevo ciclo neoliberal de desvalorización y exclusión del campesinado se ha llevado a cabo en tres etapas: 1) las reformas estructurales de primera generación (1982-1988); 2) las reformas estructurales de segunda generación (1988-1994), y 3) las reformas estructurales de tercera generación (2012-2016). A continuación se reseña cada una de estas etapas, poniendo mayor énfasis en esta última.

1. Reformas estructurales de primera generación (1982-1988). A raíz de la crisis de la deuda de 1982, en la cual nuestro país se vio imposibilitado de cumplir las obligaciones crediticias con el exterior debido a la caída de los ingresos petroleros y la elevación de las tasas de interés, el nuevo gobierno de Miguel de la Madrid aceptó una renegociación con los acreedores internacionales, el Tesoro de los Estados Unidos y el FMI, condicionada a un cambio radical en la política macroeconómica del país. Dichos cambios fueron "negociados" en los llamados Programas de Ajuste Estructural. En adelante, la nueva política macroeconómica y la política agroalimentaria debían regirse por los principios 
neoliberales de "libre mercado", apertura comercial, ventajas comparativas, privatización de la economía, austeridad, venta de activos gubernamentales, desregulación de la actividad económica y prioridad a la inversión privada y extranjera.

El desfalleciente Estado de bienestar fue obligado a dar paso a la mercadocracia que impone el desmantelamiento de la agricultura mexicana y deja a los campesinos en manos de las fuerzas invisibles del mercado, del laissez faire, laissez passer, y de la libre competencia en un capitalismo global en ascenso y crecimiento acelerado.

La austeridad neoliberal impuesta para el pago de la deuda externa se reflejó en la caída de la inversión pública productiva al sector agropecuario, en el recorte del presupuesto rural, en la progresiva supresión de programas de fomento productivo para el campo, así como en la liquidación y venta de empresas paraestatales vinculadas al sector.

Paralelamente, se inició el desmantelamiento de la protección arancelaria de los productos agroalimentarios y, en 1985, nuestro país ingresó al Acuerdo General de Aranceles y Tarifas —GATT, antecesor de la Organización Mundial de Comercio- con lo que se puso fin al modelo de autosuficiencia alimentaria y sustitución de importaciones para dar paso al modelo agroexportador y de dependencia alimentaria.

El abandono del campo en esta primera etapa de reformas estructurales se tradujo en un mayor deterioro de los términos de intercambio campo-ciudad; en la supresión del extensionismo agrícola; en la desaparición de los precios de garantía con excepción del maíz y frijol; en el desplome del crédito y seguro agrícolas; en importaciones agroalimentarias crecientes; en la caída del producto interno bruto del sector primario, y en el crecimiento de la migración rural.

2. Reformas estructurales de segunda generación (1988-1994). Durante el periodo de gobierno del presidente Carlos Salinas de Gortari (19881994) se emprendió la mayor ofensiva contra los campesinos desde tiempos del Porfiriato. Fueron cuatro los ejes de la embestida salinista contra los campesinos: i) la contrarreforma del artículo 27 constitucional; ii) el Tratado de Libre Comercio de América del Norte (TLCAN); iii) el desmantelamiento de las instituciones y programas de fomento $y$ 
regulación agroalimentaria; y iv) la trasmutación ideológica de los campesinos de sujetos productivos a pobres y a población redundante, objeto de programas asistencialistas individualizantes y clientelares.

Dado que los tres primeros ejes han sido abordados con profundidad por diversos autores, ${ }^{7}$ en el presente artículo se analizará el cuarto eje antes señalado.

En el marco del discurso sobre la integración de bloques económicos regionales y la globalización, el gobierno de Salinas de Gortari y sus ideólogos más connotados, Santiago Levy y Luis Téllez, establecieron las siguientes tesis para la modernización del sector agropecuario: i) la pobreza rural se explica por el gran tamaño de la población rural - 25$30 \%$ del total nacional- en relación con su aportación al Producto Interno Bruto, PIB — de 3 a 5\%-. Por tanto, la población rural debe descender al nivel de los países en desarrollo — de 3 a 5\%—; ii) la única vía para la modernización del campo y para hacer frente a la competencia de Estados Unidos y Canadá es la sustitución del minifundio por grandes unidades de producción a través del mercado privado de tierras; iii) las grandes unidades de producción rural son las únicas que pueden sobrevivir y ser competitivas en el marco del TLCAN; iv) las pequeñas y medianas unidades de producción rural no son competitivas, son pobres e improductivas y, por lo tanto, deben desaparecer. En tanto esto sucede, deben recibir transferencias condicionadas para combatir la pobreza. De ahí la creación del emblemático programa de Solidaridad.

A los grandes agricultores se les reconoció como los únicos capaces de "modernizarse" y ser competitivos en el marco del TLCAN, concentrando en ellos la mayor parte de la inversión pública productiva, los subsidios, el crédito, los apoyos a la comercialización y la investigación pública. A partir del salinato, los grandes agricultores

\footnotetext{
${ }^{7}$ Entre otros, por José Luis Calva (1993), La disputa por la tierra. La reforma del Artículo 27 y la nueva ley agraria, Editorial Fontamara, México; Armando Bartra (2003a), Cosechas de ira. Economía politica de la contrarreforma agraria, ITACA/Instituto Maya, A.C., México; y (2003b), "El campo mexicano ante la globalización" (conferencia magistral), Universidad Autónoma Chapingo, México; Víctor Suárez Carrera (2005), ¿Tiene futuro la agricultura campesina en México? Políticas públicas para la soberanía alimentaria y el desarrollo rural con campesinos. Cámara de Diputados/Centro de Estudios para el Desarrollo Rural Sustentable y la Soberanía Alimentaria, México.
} 
y las corporaciones agroalimentarias pasaron a ser, parafraseando a Arturo Warman, los nuevos hijos predilectos del régimen.

De 1990 a la fecha, cambió la proporción entre programas productivos y programas asistencialistas del presupuesto rural federal: descendió la inversión productiva y aumentó el presupuesto para programas de transferencias condicionadas de combate a la pobreza. Como muestra de lo anterior, de 2005 a 2017 el porcentaje de la vertiente de Competitividad en el Programa Especial Concurrente para el Desarrollo Rural (PEC Rural) pasó de $27.5 \%$ a $14.6 \%$, mientras que la vertiente Social se incrementó de $14.2 \%$ a $32.2 \%$ en el mismo periodo. ${ }^{8}$ La política neoliberal hacia el campo podría sintetizarse en la siguiente afirmación: inversión productiva para los ricos y programas asistencialistas para los pobres. ${ }^{9}$

3. Reformas estructurales de tercera generación (2012-2016). Con el arribo de Enrique Peña Nieto (EPN) a la presidencia de la república en 2012 se abre una nueva etapa de dominio abierto del capital transnacional —un verdadero cambio de época — en la vida política y económica del país.

Este hecho no resultó una sorpresa. Fue advertido puntualmente por los partidos y movimientos de oposición. De hecho, las elecciones presidenciales de 2012 representaron abiertamente una disputa por la nación entre las fuerzas progresistas, nacionalistas y democráticas, y las fuerzas del capital transnacional y sus operadores políticos locales.

Vivimos en la etapa del capitalismo global caracterizada "por un sistema de producción, una clase y un Estado trasnacional en ciernes, que subsume los circuitos de acumulación nacionales a los circuitos globales, y subordina las clases y fracciones de clase capitalistas y a los Estados nacionales a la naciente clase capitalista trasnacional y al Estado trasnacional en formación, respectivamente" (Robinson, 2013: 21-56).

\footnotetext{
${ }^{8}$ Rangel, Gabriela, 2016, con información de la Cámara de Diputados, mimeo. Las cifras para 2017 corresponden al Proyecto de Presupuesto de Egresos de la Federación 2017 que envió el Ejecutivo Federal a la Cámara de Diputados el pasado 8 de septiembre de 2016.

${ }^{9} \mathrm{Al}$ respecto, hay numerosas evidencias proporcionadas por Héctor Robles, las cuales se pueden consultar en el portal Subsidios al Campo (www.subsidiosalcampo.org.mx) y en la Iniciativa Valor al Campesino (www.valoralcampesino.org).
} 
Se imponen nuevos patrones de acumulación que impulsan una inédita movilidad global del capital por la vía de la expansión territorial y la intensificación de la mercantilización de bienes públicos que estaban bajo el control del Estado y de las colectividades sociales. Se obliga, también, a la precarización e informalización global del trabajo e, incluso, se recurre a formas de acumulación aparentemente ya superadas en lo que David Harvey llama "acumulación por desposesión de territorios y recursos naturales”, acompańada de un modelo neoextractivista rampante.

De esta forma, con el regreso del Partido Revolucionario Institucional (PRI) a la presidencia de la república en 2012, se pone fin al Pacto Social Estado-campesinos, al Estado mexicano nacionalista, desarrollista y de bienestar surgido de la Revolución, de la postguerra y de la Guerra Fría, abriendo paso a un nuevo Estado neocolonial capturado por la agenda del capital trasnacional.

Ofensiva trasnacional contra la propiedad social de la tierra. En este contexto, el Congreso de la Unión aprobó en 2012 las llamadas reformas estructurales a iniciativa del presidente de la república y con el respaldo de las fuerzas políticas del llamado Pacto por México - PRI, PAN, PRD —. Las reformas aprobadas — laboral, educativa, telecomunicaciones, financiera, fiscal, política y energética- se inscriben claramente en el marco de una ofensiva del capital transnacional en México - y el mundo entero- para el control de los recursos energéticos, minerales, hidráulicos y agroalimentarios, y para ampliar la movilidad del capital, la protección absoluta de las inversiones y de la propiedad intelectual de las corporaciones, la privatización de los servicios públicos y la precarización del trabajo asalariado e informal.

Entre todas estas contrarreformas, desde el punto de vista del interés nacional y de la sociedad sobresale la reforma constitucional en materia de energía que, como es sabido, no solamente reduce la renta petrolera y entrega los hidrocarburos de la nación al capital transnacional sino que también aprueba la llamada ley Peña de desamortización de tierras campesindias.

Con esta ley se reproducen, bajo nuevas formas, los mismos patrones de subordinación y despojo de los recursos de la nación y de las 
comunidades campesindias que prevalecieron durante el Porfiriato y, en parte, durante la reforma liberal.

Ahora, en pleno siglo XXI, con la contrarreforma constitucional en materia de energía, se promulga en su artículo Octavo transitorio la versión Peña de la Ley Lerdo de desamortización de bienes de las corporaciones civiles —y religiosas — de 1856 y de la ley porfiriana de colonización y compañías deslindadoras de 1883.

Efectivamente, bajo similar ideología a la porfiriana —ideología liberal-positivista-extranjerizante-, se endereza una nueva ofensiva contra la propiedad social de la tierra y los recursos de las comunidad campesinas e indígenas con el argumento liberal-porfirista de que las tierras y recursos en manos campesindias son "bienes en manos muertas", y que "si queremos progreso" deben privatizarse y entregarse a "manos vivas", o sea, al capital energético y minero transnacional.

En efecto, en dicha reforma se establece que las actividades de exploración y explotación de petróleo y gas, así como toda la industria de hidrocarburos, son actividades estratégicas y de interés social y orden público y, por tanto, tienen prioridad y preferencia sobre cualquier otra actividad que se realice en el suelo y subsuelo de territorio nacional. A la letra, el artículo Octavo transitorio de dicha reforma constitucional establece lo siguiente:

Derivado de su carácter estratégico, las actividades de exploración y explotación del petróleo y demás hidrocarburos, así como el servicio público de transmisión y distribución de energía eléctrica, a que se refiere el presente Decreto, se considera de interés social y orden público, por lo que tendrán preferencia sobre cualquier otra que implique el aprovechamiento de la superficie y del subsuelo de los terrenos afectos a aquellas.

La ley preverá los términos y condiciones generales de la contraprestación que se deberá cubrir por la ocupación o afectación superficial o, en su caso, la indemnización respectiva (negritas del autor).

Adicionalmente, en las leyes secundarias se establece que las actividades mineras no tendrán prioridad sobre las actividades de exploración 
y explotación de petróleo y gas, pero sí sobre cualquier otra actividad que se realice en el suelo y subsuelo de los territorios concesionados a las corporaciones mineras. Para tal efecto se establecieron, entre otros procedimientos de "desamortización y deslinde de terrenos baldíos", figuras tales como "reservas nacionales", "servidumbre legal de hidrocarburos", "contratos de ocupación y de expropiación" por causa de utilidad privada a favor de las empresas extranjeras con asignaciones, contratos, autorizaciones y permisos de exploración y explotación de hidrocarburos.

Se observa con claridad y sin lugar a duda el nuevo papel asignado al campo y a los campesindios: no son estratégicos ni prioritarios el campo, la agricultura, los campesinos y las campesinas, los ejidos y comunidades, las pequeñas propiedades, los pueblos indígenas, los modos de vida rurales, la biodiversidad, los recursos hídricos, los sitios históricos y ceremoniales, la autosuficiencia alimentaria, la soberanía y seguridad alimentaria y nutricional, los derechos al trabajo y a no migrar, los derechos a la propiedad, los derechos a la alimentación y a un medio ambiente sano.

Ni siquiera están en un segundo orden de prioridad, porque este lugar lo ocupa la minería.

La estrategia se orienta a que los campesindios acepten romper con sus comunidades y ejidos para individualizarse, que reconozcan que no tienen lugar en el proyecto nacional, que entreguen sin resistencia sus tierras y sus recursos considrando como únicas alternativas la migración y la economía ilegal. Para la agenda corporativa transnacional y parafraseando a Porfirio Díaz, la consigna para los campesindios y en general para la población rural es: ¡emígrenlos en caliente!

De esta forma, se busca culminar las reformas estructurales de primera generación que emprendió Miguel de la Madrid y las contrarreformas agrarias de segunda generación que iniciaron con el salinato entre 1988 y 1994 mediante la modificación al artículo 27 constitucional, el TLCAN y el abandono del campo.

Con la contrarreforma agraria vía la reforma energética, se pretende acabar con la propiedad social de la tierra, promover su reconcentración 
en pocas manos, intensificar la expulsión de la población rural, debilitar la resistencia social frente al despojo de los recursos naturales de la nación y de los campesinos y pueblos indígenas, y profundizar la dependencia e inseguridad alimentaria y nutricional del país. Lo anterior, para servir a la agenda de los neohacendados — las empresas energéticas y mineras-, el capital corporativo transnacional y a la estrategia de seguridad energética de los Estados Unidos.

Y ahora, para completar y favorecer el despojo del petróleo de la nación y debilitar las resistencias campesindias, han optado por dar un nuevo impulso a la privatización de la propiedad social de la tierra.

Ésta ha sido una vieja demanda histórica del bloque conservadorneoliberal a lo largo de un siglo: primero con la oposición maderistacarrancista al Plan de Ayala, la guerra contra los ejércitos campesinos del Sur y Norte, y el asesinato de Zapata y Villa. Después con el congelamiento del reparto agrario por los gobiernos "revolucionarios" norteños — de 1920 a 1934_. En el Cardenismo, con la oposición violenta de hacendados a la aceleración y masificación del reparto agrario. Más tarde, con la primera contrarreforma agraria de Ávila Camacho y Miguel Alemán y sus certificados de inafectabilidad agrícola y ganadera —1940-1952-. Y luego, con la imposición del modelo neoliberal en 1982, su profundización durante el salinato y la contrarreforma al artículo 27 constitucional, el TLCAN y el abandono del campo.

Y no han podido. Ni siquiera con la contrarreforma constitucional salinista que impulsaba la privatización masiva del ejido y la comunidad.

En efecto, de acuerdo con Héctor Robles, de 1992 a 2012 únicamente pasaron a dominio pleno tres millones de hectáreas ejidales y comunales de un total de 106 millones de hectáreas, es decir, 2.8\%, y sólo se han constituido sociedades mercantiles con propiedad rústica en no más de 200 mil hectáreas (Robles, 2012: 321).

Tal y como lo afirmara Arturo Warman, ${ }^{10}$ los campesinos han contradicho una y otra vez desde tiempos de la Colonia las recurrentes e ininterrumpidas ofensivas desde el poder para despojarlos de sus tierras y privatizar el ejido y la comunidad.

\footnotetext{
${ }^{10}$ Warman, Arturo (1976), Y venimos a contradecir: los campesinos de Morelos y el estado nacional, CIS/INAH, México.
} 
La más reciente ofensiva al respecto inició en las postrimerías del calderonato y su iniciativa de modificación de la Ley Agraria del 27 de noviembre de $2012^{11}$ para quitar los candados a la privatización acelerada del ejido y la comunidad, para "desburocratizarla" y "simplificarla”, que siguió con el sexenio encabezado por Peña Nieto. De entrada, como un primer aviso, desapareció la Secretaría de la Reforma Agraria y creó en su lugar la Secretaría de Desarrollo Agrario, Territorial y Urbano (Sedatu), para promover la "desamortización” del ejido y la comunidad y "ordenar" el cambio del uso agrario del suelo. Enseguida, continuó con la política neoliberal de abandono del campo y privilegió a la minoría de agricultores rentistas de riego y a los monopolios agroalimentarios. Después vino la ley Peña de desamortización de tierras campesindias antes referida.

\section{Resistencia campesindia en defensa de la tierra, el agua y la vida.} Hoy como ayer, las comunidades campesinas e indígenas resisten los intentos de despojo y privatización impulsados por una coalición de fuerzas nunca antes vista en la historia de lucha por la tierra: las fuerzas del capital transnacional aliadas con la oligarquía mexicana y sus operadores políticos.

La ofensiva privatizadora está en marcha y la enfrentan decenas de luchas campesindias locales y regionales contra expropiaciones ilegales, asambleas fraudulentas para legitimar el dominio pleno, concesiones mineras, permisos ilegales para hidroeléctricas y parques eólicos... Se avecinan decenas de asignaciones y contratos para la exploración y explotación de petróleo y gas y para el tendido de poliductos y líneas de transmisión eléctrica. El caso de Atenco y el anuncio de la construcción del nuevo aeropuerto internacional de la Ciudad de México son emblemáticos de lo que nos espera si no se acumulan y se organizan de mejor manera las fuerzas locales, regionales y nacionales, tanto del campo como de la ciudad.

En este sentido, destaca la iniciativa de la Campaña Sin Maíz No hay País y decenas de organizaciones y movimientos del campo y de

\footnotetext{
11 Véase, http://calderon.presidencia.gob.mx/iniciativas-de-ley/iniciativa-que-reforma-adiciona-y-deroga-diversas-disposiciones-de-la-ley-agraria/
} 
la ciudad para impulsar las jornadas nacionales, estatales y regionales en defensa de la tierra, el trabajo, la vida y el agua, como parte de una estrategia de mediano y largo plazo para impulsar una mayor y mejor articulación de fuerzas y aumentar la capacidad de los movimientos sociales con los que resistir la privatización de la tierra, enfrentar el despojo de nuestros recursos naturales, revertir las contrarreformas estructurales, cambiar el régimen autoritario y neoliberal, y avanzar hacia la construcción de un nuevo proyecto alternativo de nación.

\section{Hacia la segunda revalorización campesindia en México}

La ofensiva neoliberal que canceló la primavera campesindia e hizo pedazos el pacto histórico y constitucional entre el Estado revolucionario y los campesinos no ha sido fácil. Hoy como ayer, ha enfrentado a lo largo y ancho del país múltiples y persistentes resistencias desde el México profundo y desde las orillas del capitalismo global. Además de oponerse al despojo, la exclusión y el genocidio, estas resistencias construyen alternativas y proponen una nueva y profunda revalorización de sus modos de producción, vida y cultura de cara a un nuevo proyecto de nación y a los desafíos civilizatorios planteados por la gran crisis del capitalismo global.

Entre las múltiples resistencias y construcción de alternativas para la revalorización campesindia, se pueden citar, entre muchas otras, las siguientes: movimientos campesinos por el control de los procesos económicos y la comercialización; movimientos de las comunidades contra las concesiones de bosques y selvas a empresas privadas y paraestatales y a favor del manejo forestal comunitario; movimientos campesinos contra las reformas al artículo 27 y el TLCAN; organización de pequeńos cafetaleros para el control del proceso productivo y comercial; movimiento campesindio por la agricultura orgánica y el comercio justo; insurrección neozapatista (EZLN) por los derechos y autonomía de los pueblos indígenas; resistencias campesindias contra la privatización de la tierra y el agua; movimientos por la igualdad de género y contra la violencia contra las mujeres en el medio rural; movimientos sociales contra el despojo de los territorios y sus recursos naturales; movimiento "El campo no aguanta más" contra el TLCAN, la soberanía alimentaria 
y la revalorización de la agricultura campesina; la Red Mexicana de Afectados por la Minería (REMA) contra los megaproyectos mineros a cielo abierto; Campańa "Sin maíz no hay país" por la soberanía alimentaria, la agricultura campesina y en contra del maíz transgénico; defensa de semillas nativas, recursos genéticos y conocimientos campesinos, indígenas y comunitarios; la convergencia de organizaciones en torno al Plan de Ayala para el Siglo XXI; movimientos en defensa de los derechos humanos de campesinos, indigenas y población rural; milpa, chinampa, agricultura sostenible de ladera, maíz intercalado con frutales - MIAF_-; ordenamientos territoriales campesinos; movimientos identitarios y por la multiculturalidad; luchas de los jornaleros agrícolas por los derechos laborales y vida digna; movimientos por la autonomía y el autogobierno comunitario de los territorios; movimiento ciudadano contra la privatizacion del agua y por una ley de aguas para todos y para la vida; movimientos de jornaleros y migrantes transterritorializados; movimiento de tianguis orgánicos y mercados locales; modelo de agricultura campesina de conocimientos integrados; acción colectiva contra las siembras de maíz transgénico; iniciativa Valor al Campesino; convergencia de organizaciones y movimientos contra el Acuerdo de Asociación Transpacífico - TPP, por sus siglas en inglés-, entre otros.

Adicionalmente, en el terreno político, los campesindios al lado de los urbanos han intentado cambiar de régimen neoliberal en las elecciones presidenciales de 1988, 2016 y 2012, respaldando opciones antineoliberales, democráticas, nacionalistas y progresistas. Y seguramente lo harán con más éxito en las elecciones presidenciales de 2018.

En otras palabras, el campesindio, a pesar de todo, ha resistido y sigue resistiendo la ofensiva neoliberal, y está empeñado en conquistar su segunda revalorización en la historia de México.

La lucha por la segunda revalorización del campesinado mexicano tiene como objetivo central lograr el respeto, revaloración y apoyo del Estado y de la sociedad a los campesinos y pueblos indígenas como sujetos de derechos y sujetos productivos, formando parte de un nuevo proyecto nacional.

Más allá de reivindicar la centralidad del pequeño productor en una nueva política de Estado para el campo mexicano, como lo viene 
impulsando la Iniciativa Valor al Campesino —entre otras-, conviene precisar que no se trata sólo de un acto de justicia y solidaridad, sino de un asunto de sobrevivencia, derechos plenos y buena vida para todos los mexicanos de hoy y de las futuras generaciones.

Se trata de dilucidar si existe una salida democrática y sostenible a la crisis estructural del modelo agroalimentario y de gestión de los territorios rurales impulsado por el capital transnacional o si, a través del autoritarismo, se impondrá en nuestro país su continuidad agónica, prolongando y agravando la crisis alimentaria, social, ambiental, de seguridad y gobernabilidad que nos aqueja desde hace más de dos décadas, particularmente desde la entrada en vigor del TLCAN y el estallamiento de la crisis alimentaria internacional de 2008.

Los campesindios han mostrado en estos años que existen alternativas al modelo neoliberal viables y probadas tanto en el terreno productivo como en el de la gestión y manejo sustentable de los territorios rurales y sus recursos naturales.

En relación con el tema productivo y ante el agotamiento del modelo agroalimentario de la revolución verde, conviene preguntarse: i) ¿quiénes producirán los alimentos que demanda la población, en la cantidad y calidad requeridas?; ii) ¿quiénes producirán alimentos sanos y nutritivos, que no produzcan enfermedades; iii) que sean producidos en forma tal que no envenenen la tierra, el agua y el aire; iv) que su producción, procesamiento y distribución no suponga incrementar el calentamiento del clima planetario, sino por el contrario, contribuya a enfriarlo; v) que el respeto a los derechos humanos sea la norma en el proceso productivo y no la excepción; vi) que su producción respete y preserve no sólo la biodiversidad sino sobre todo la diversidad cultural de quienes los producen; vii) que su producción disminuya la desigualdad y promueva una justa retribución al trabajo; y, viii) que, en síntesis, produzcan no solamente alimentos, sino dignidad y buena vida para todos?

Los campesinos y pueblos indígenas del país muestran que soló con un cambio paradigmático del modelo de agricultura de revolución verde, los pequeños productores pueden responder afirmativamente a estas preguntas y desafíos. 
$\mathrm{Al}$ respecto conviene ejemplificar con el caso de la agricultura maicera sinaloense, paradigma del supuesto éxito de la revolución verde y cuyos grandes agricultores rentistas son ahora los beneficiarios del régimen. Hace 25 años, Sinaloa producía no más de 500 mil toneladas de maíz; ahora, alrededor de 15 mil productores - la mayoría rentistas- producen 5 millones de toneladas en 500 mil hectáreas de riego. Es decir, tienen un rendimiento promedio de 10 toneladas por hectárea. La mayor parte de la producción se destina a abastecer el mercado nacional en una época en que no hay producción significativa de maíz blanco en ninguna otra parte del país. De ahí la importancia de la agricultura sinaloense. Sin embargo, los costos de producción son muy altos: tres mil pesos por tonelada en virtud del uso masivo de semillas híbridas, de fertilizantes y agroquímicos, de maquinaria agrícola, diesel y agua de riego. Para compensar los elevados costos de producción y baja rentabilidad, cada año los productores sinaloenses reciben subsidios públicos en cantidades crecientes. Tan solo en 2015 recibieron cuatro mil millones de pesos que representan el $50 \%$ del presupuesto anual de Aserca-Sagarpa. En contraste, un millón de pequeños productores recibieron cuatro mil millones de pesos del programa ProcampoProagro en ese mismo año.

Si comparamos el subsidio que reciben los maiceros de Chiapas, Guerrero o Oaxaca, la diferencia es importante: más de $\$ 250,000 /$ productor en Sinaloa contra $\$ 12,500$ /productor en Chiapas, $\$ 7,900 /$ productor en Guerrero y \$5,500/productor en Oaxaca. Como vemos, se trata de subsidios públicos para la desigualdad y la exclusión. Con la devaluación reciente del peso frente al dólar, los costos de producción de la agricultura sinaloense se incrementarán en al menos $40 \%$, por lo que los requerimientos de subsidio ascenderán de nueva cuenta y así sucesivamente. Es decir, no hay presupuesto que alcance para sostener este modelo.

Por si fuera poco, el subsidio al productor sinaloense está asociado a la obligación de vender las cosechas a precios bajos a los grandes compradores - Maseca y Cargill—, lo que no se refleja en la disminución de los precios al consumidor de la harina y la tortilla. El subsidio al productor finalmente se lo embolsan los compradores y no repercute en el consumidor final, sino en las ganancias de los monopolios 
agroalimentarios, por lo que este modelo no es sostenible desde el punto de vista del interés público.

Por otro lado, el uso masivo de agroquímicos y de energéticos fósiles de la agricultura maicera sinaloense contamina el suelo, el agua, los alimentos, y emite grandes cantidades de gases de efecto invernadero (GEI), lo que a su vez amenaza la biodiversidad y la salud de los trabajadores agrícolas. Lo anterior, sin contar con las emisiones de GEI derivadas de la importación de insumos —urea desde Ucrania—y de la distribución del maíz sinaloense por todo el territorio nacional, incluyendo transporte marítimo vía el Canal de Panamá.

Por supuesto que la fase transgénica de la revolución verde no hace más que reproducir y agravar los problemas ya comentados.

No obstante hay alternativas económicas, sociales y ambientales viables y probadas: la revalorización y fomento del enorme potencial productivo del pequeño productor asociada a la adopción de un nuevo modelo de agricultura sostenible, agroecológica, de conocimientos integrados y de una nueva política de Estado que lo promueva.

Lo anterior significa, por un lado, incorporar en el esfuerzo productivo a cinco millones de unidades de producción rural, con lo que el impacto en la producción nacional se verá reflejado en el corto plazo. Por otro lado, la adopción de un modelo de agricultura campesina de conocimientos integrados — el llamado modelo ACCI_, permite impulsar la productividad en forma sostenible a partir ya no de insumos sino de conocimientos integrados: los conocimientos de la sabiduría campesina ancestral con los conocimientos científicos y tecnológicos de punta. Reconociendo el carácter del campesino como sujeto productivo y portador de conocimientos agrícolas pertinentes y la intrínseca característica del suelo como ecosistema vivo en un contexto de complejidad creciente, es posible impulsar un nuevo modelo de agricultura de inclusión social, altos rendimientos, bajos costos, mayor rentabilidad, protección de los recursos, mayor resiliencia de los cultivos y menor emisión de GEI.

Bajo este nuevo modelo, pequeños productores de maíz de temporal de una organización campesina de nuevo tipo, la Asociación Nacional de Empresas Comercializadoras de productores del Campo, ANEC 
(www.anec.org.mx), obtienen 10 toneladas/hectárea de temporal con costos de producción de $\$ 1,000 /$ tonelada. Lo hacen utilizando los conocimientos integrados como factor principal de la productividad y resiliencia, produciendo localmente los bioinsumos — semillas, compostas, lixiviados, microorganismos, extractos vegetales, extractos vegetales, inductores de resistencia, harinas de roca, etcétera-, res-tableciendo el equilibrio en el ecosistema suelo, protegiendo la biodiversidad, profesionalizando permanentemente a productores y técnicos comunitarios, y sobre todo, bajo la coordinación y apoyo de su organización local autónoma, para de esta forma reducir la dependencia y aumentar autonomía, libertad y ciudadanía.

Hay innumerables ejemplos del potencial productivo del campesinado: producción orgánica, milpa "recargada”, agricultura chinampera, maíz intercalado con árboles frutales — sistema MIAF_, agricultura sostenible de ladera, manejo comunitario de bosques y selvas, turismo agroecológico, defensa y preservación de los maíces e innumerables plantas alimenticias nativas, protección de las cuencas hidrológicas y de los manantiales y cuerpos de agua, manejo sustentable de agaves para la producción de mezcal, por ejemplo.

El potencial productivo multifuncional, diversificado y sostenible del pequeño productor está a la mano, no hay otra salida democrática y sostenible a la crisis del modelo de agricultura de la revolución verde. Urge incorporar el fomento productivo del pequeño productor a nivel de política de Estado en la agenda del movimiento campesino.

Además de la puesta en marcha de una nueva revolución tecnológica para la producción agroalimentaria como la antes descrita, la segunda revalorización campesina exige también garantizar el respeto a la propiedad social de la tierra y a los derechos de los campesindios a sus territorios, base material de la existencia y la reproducción de las agriculturas campesinas en México.

$\mathrm{Al}$ respecto, en el México profundo se vive una intensa y multifacética resistencia contra el capital transnacional que, con el apoyo de los tres niveles de gobierno, intenta despojar y depredar los territorios campesindios para impulsar megaproyectos al margen de preceptos normativos como la consulta con consentimiento libre, previo e 
informado: minería a cielo abierto, fractura hidráulica — frackingen yacimientos de petróleo y gas esquisto, exploración y explotación de yacimientos convencionales de hidrocarburos, privatización de ríos y manantiales para el abastecimiento del fracking y la minería tóxica, complejos turísticos, desarrollos inmobiliarios, carreteras, áreas naturales privadas, entre otros.

Y no es sólo la resistencia frente al despojo, sino la construcción de alternativas campesindias de preservación y manejo comunitario de los territorios y sus recursos naturales, como lo han mostrado las comunidades neozapatistas en Chiapas, la cooperativa Tosepan Titatanieke en la Sierra Norte de Puebla, las comunidades forestales en diversos estados, las policías comunitarias de Guerrero, los comuneros de Cherán, las tribus yaquis en Sonora, los me' phaa en la Montańa de Guerrero, las comunidades ikoots del Istmo de Tehuantepec, los comuneros y ejidatarios del sur de la Ciudad de México, entre muchos otros.

La segunda revalorización de los campesinos y pueblos indígenas en la historia de México será conquistada tarde o temprano, nos urge a todos: a los propios campesindios, a los urbanos, al país en su conjunto, $\mathrm{y}$ a los mexicanos y mexicanas de las siguientes generaciones.

Y para esto, los campesindios tendrán que conformar un nuevo bloque histórico antineoliberal, nacionalista, democrático, social y de derechos con muchas otras fuerzas sociales y políticas del país.

Las elecciones presidenciales de 2018, a un siglo del inicio de la primavera campesindia, pueden ser el catalizador de la conformación de dicho bloque histórico y el punto de quiebre para lograr la segunda revalorización del campesinado en México. 
Cuadro. Reparto Agrario1910-1992

\begin{tabular}{|c|c|c|c|c|c|c|c|}
\hline \multicolumn{8}{|c|}{$\begin{array}{l}\text { Dotación de tierras y beneficiarios según tipo de tierra por periodos presidenciales } \\
\text { Periodos seleccionados de } 1900-1914 \text { a } 1989-1992\end{array}$} \\
\hline \multirow{2}{*}{ Periodo } & \multicolumn{7}{|c|}{ Tipo de tierra (ha) } \\
\hline & Total & Riego & Temporal & Agostadero & Monte & Desértica & Indefinida \\
\hline Total & 107497458 & 1994706 & 13026954 & 57957453 & 11352074 & 1112101 & 22054170 \\
\hline $1900-1914$ & 194495 & 27194 & 17976 & 58749 & 18399 & 16987 & 55190 \\
\hline $1915-1934$ & 11580833 & 247645 & 1387258 & 2046772 & 1509623 & 189376 & 6200159 \\
\hline $1935-1940$ & 18786131 & 937401 & 3382696 & 9438337 & 3692972 & 302539 & 1032186 \\
\hline $1941-1946$ & 7287697 & 95844 & 1007955 & 3925151 & 1410933 & 9480 & 838334 \\
\hline $1947-1952$ & 4633321 & 62212 & 738268 & 2665085 & 834491 & 36733 & 296532 \\
\hline 1953-1958 & 6056773 & 78618 & 902624 & 2973597 & 632685 & 898 & 1468351 \\
\hline 1959-1964 & 8870430 & 158985 & 1354374 & 5527498 & 579247 & 17612 & 1232714 \\
\hline $1965-1970$ & 24738199 & 71821 & 2039807 & 16124843 & 1773604 & 82153 & 4645971 \\
\hline $1971-1976$ & 12773888 & 111098 & 657243 & 7533326 & 343605 & 171699 & 3956917 \\
\hline $1977-1982$ & 6397595 & 79654 & 871084 & 4012597 & 220677 & 42502 & 1171081 \\
\hline 1983-1988 & 5626227 & 83091 & 537843 & 3456346 & 293608 & 224193 & 1031146 \\
\hline $1989-1992$ a & 551869 & 41143 & 129826 & 195152 & 42230 & 17929 & 125589 \\
\hline
\end{tabular}

\begin{tabular}{lrr}
\hline Periodo & Dotaciones & Beneficiarios \\
\hline Total & 42195 & 3118019 \\
$1900-1914$ & 142 & 11738 \\
$1915-1934$ & 7000 & 866161 \\
$1935-1940$ & 10975 & 728847 \\
$1941-1946$ & 3575 & 157816 \\
$1947-1952$ & 1999 & 80161 \\
$1953-1958$ & 1917 & 68317 \\
$1959-1964$ & 2341 & 148238 \\
$1965-1970$ & 4420 & 278214 \\
$1971-1976$ & 2311 & 205999 \\
$1977-1982$ & 3563 & 243350 \\
$1983-1988$ & 3565 & 248486 \\
$1989-1992$ a & 387 & 80692 \\
\hline
\end{tabular}

a) Cifras al 21 de febrero de 1992.

Fuente: Secretaria de la Reforma Agraria, Dirección General de Información y Documentación Agraria. 


\section{Bibliografía citada}

Acuerdo Nacional para el Campo. Por el desarrollo de la Sociedad Rural y la Soberania y Seguridad Alimentaria, 2003, México.

Bartra, Armando, 2003a, Cosechas de ira. Economía politica de la contrarreforma agraria, ITACA/Instituto Maya, A.C., México.

Bartra, Armando, 2003b, "El campo mexicano ante la globalización” (conferencia magistral), Universidad Autónoma Chapingo, México.

Bartra, Armando, 2006, El capital en su laberinto. De la renta de la tierra a la renta de la vida, Universidad Autónoma de la Ciudad de México/ÍTACA/ Centro de Estudios para el Desarrollo Rural Sustentable y la Soberanía Alimentaria, México.

Bartra, Armando, 2014, El hombre de hierro. Limites sociales y naturales del capital en la perspectiva de la gran crisis, UACM/ÍTACA/ UAM, México.

Bonfil Batalla, Guillermo, 1989, México profundo. Una civilización negada, Secretaría de Educación Pública/Centro de Investigaciones y Estudios Superiores en Antropología Social, México.

Calva, José Luis, 1993, La disputa por la tierra. La reforma del Artículo 27 y la nueva Ley Agraria, Fontamara, México.

Córdova, Arnaldo, 1973, La ideología de la Revolución Mexicana. La formación del nuevo régimen, Ediciones Era, México.

De Sousa Santos, Boaventura, 2009, Una epistemología del Sur, Siglo XXI Editores/CLACSO, México.

León-Portilla, Miguel, 2011, Independencia, Reforma, Revolución, ¿y los indios qué?, Conaculta/Instituto de Investigaciones HistóricasUNAM, México.

Montoya, Alberto, Gonzalo Nuñez y Azael Cisneros (coautores), 2015, Estrategia de reindustrialización ecelerada en México, Senado de la República/LIMUSA, México.

Rangel, Gabriela, 2016, con información de la Cámara de Diputados, mimeo.

Robinson, William I., 2013, Una teoría sobre el capitalismo global, Siglo XXI Editores, México. 
Robles Berlanga, Héctor, 2012, Mercado de tierras en América Latina. Concentración y extranjerización de tierras. El caso de México, FAO, Roma.

Suárez Carrera, Víctor, 2011, Políticas públicas para la agricultura mexicana. Con base en el consenso y la certidumbre: el caso de la Ley de Planeación para la Soberanía y la Seguridad Agroalimentaria y nutricional, ANEC/ÍTACA, México.

Warman, Arturo, 1976, Y venimos a contradecir: los campesinos de Morelos y elestado nacional, CIS/INAH, México.

\section{Referencias hemerográficas}

Bartra, Armando (coordinador), 2015, "Agricultura vs agronegocio. Iniciativa al valor campesino", La Jornada del Campo, Suplemento Informativo de La Jornada, núm. 95, publicación mensual, México.

Lizárraga, Pilar, Francois Houtart y Carlos Vacaflores (coordinadores), 2014, “Agricultura campesina en Latinoamérica. Diálogo del Encuentro Latinoamericano del Grupo de Trabajo 'Decolonialidad, Disputas Territoriales y Desarrollo Rural'”, Diversitas 1. Revista de Pensamiento Crítico, Foro Mundial de Alternativas —Comunidad de Estudios Jaina_/CLACSO, Tarija, Bolivia. 